\title{
Inoculation Preparation Affects Survival of Salmonella enterica on Whole Black Peppercorns and Cumin Seeds Stored at Low Water Activity
}

\author{
LAUREN S. BOWMAN, KIM M. WATERMAN, ROBERT C. WILLIAMS, AND MONICA A. PONDER* \\ Department of Food Science and Technology, Virginia Tech, Blacksburg, Virginia 24051, USA
}

MS 14-483: Received 7 October 2014/Accepted 8 March 2015

\begin{abstract}
Salmonellosis has been increasingly associated with contaminated spices. Identifying inoculation and stabilization methods for Salmonella on whole spices is important for development of validated inactivation processes. The objective of this study was to examine the effects of inoculation preparation on the recoverability of Salmonella enterica from dried whole peppercorns and cumin seeds. Whole black peppercorns and cumin seeds were inoculated with S. enterica using one dry transfer method and various wet inoculation methods: immersion of spice seeds in tryptic soy broth (TSB) plus Salmonella for 24 h (likely leading to inclusion of Salmonella in native microbiota biofilms formed around the seeds), application of cells grown in TSB, and/or application of cells scraped from tryptic soy agar (TSA). Postinoculation seeds were dried to a water activity of 0.3 within $24 \mathrm{~h}$ and held for 28 days. Seeds were sampled after drying (time 0) and periodically during the 28 days of storage. Salmonella cells were enumerated by serial dilution and plated onto xylose lysine Tergitol (XLT4) agar and TSA. Recovery of Salmonella was high after 28 days of storage but was dependent on inoculation method, with 4.05 to 6.22 and 3.75 to 8.38 log CFU/g recovered from peppercorns and cumin seeds, respectively, on XLT4 agar. The changes in surviving Salmonella (log CFU per gram) from initial inoculation levels after 28 days were significantly smaller for the biofilm inclusion method $\left(+0.142_{\text {pepper }},+0.186_{\text {cumin }}\right)$ than for the other inoculation methods $\left(-0.425_{\text {pepper }},-2.029_{\text {cumin }}\right.$ for cells grown on TSA; $-0.641_{\text {pepper }},-0.718_{\text {cumin }}$ for dry transfer; $-1.998_{\text {pepper }}$ for cells grown in TSB). In most cases, trends for reductions of total aerobic bacteria were similar to those of Salmonella. The inoculation method influenced the recoverability of Salmonella from whole peppercorns and cumin seeds after drying. The most stable inoculum strategies were dry transfer, 24-h incubation of Salmonella and spices in TSB (i.e., potential inclusion of Salmonella within native microbiota biofilms), and inoculation of Salmonella cells grown on TSA subsequent to drying. However, with the dry transfer method it was difficult to obtain the large amount of inoculum needed for inactivation studies.
\end{abstract}

Spices have long been known to harbor bacteria, yeasts, and molds, and the presence of these microorganisms has been considered a product quality issue rather than a safety issue (34). Dried spice products are very low in moisture with a water activity $\left(a_{w}\right)$ of 0.20 to $0.60(13)$, which is well below the threshold that supports microbial growth (10). Although serotypes of Salmonella enterica do not grow below an $a_{w}$ of 0.93 , salmonellosis outbreaks have been attributed to contaminated peanut butter $\left(\mathrm{a}_{\mathrm{w}}=0.35\right)$, chocolate $\left(\mathrm{a}_{\mathrm{w}}=0.4\right.$ to 0.5$)$, infant cereal $\left(\mathrm{a}_{\mathrm{w}}=0.35\right.$ to $0.41)$, and a variety of spice products $(14,35,37,40)$. These outbreaks and an increasing frequency of recalls associated with Salmonella detection (41) indicate that the intrinsic low $\mathrm{a}_{\mathrm{w}}$ of these products is not sufficient to prevent transmission of foodborne pathogens.

Understanding the survival of Salmonella on spice surfaces over time is crucial because of the vulnerability of spice products, which are raw agricultural commodities, to

\footnotetext{
* Author for correspondence. Tel: 540-231-5031; Fax: 540-231-9293; E-mail: mponder@vt.edu.
}

contamination during cultivation, harvest, and storage. Spices often originate from tropical climates, many of which are in developing countries where a lack of clean water and inadequate public sanitation contribute to an increased risk for transmission of pathogens. Typical cultivation and harvest practices that could lead to contamination with Salmonella include contact with animal waste from pests and birds, contact with soil during sun drying of spice berries on the ground, and poor personal hygiene of laborers involved in hand picking and separation of berries and stalks by foot pressing (28). Elimination of all sources of contamination is impractical; therefore, it is important to improve detection and validate methods for inactivation of pathogens on spices.

An important consideration for inactivation studies should be the methods used to inoculate the product before processing. Laboratory inoculation of low-moisture foods commonly involves suspension of the pathogen in liquid followed by a drying process (6). This procedure may be problematic for some dry ingredients (e.g., nuts, spices, and powders) because the texture and $\mathrm{a}_{\mathrm{w}}$ of the product after 
wetting and drying are not equivalent to those characteristics in the original product (30). Dry transfer of inoculant from a contaminated carrier has been described for nuts $(4,7)$, ready-to-eat meats (11), and poultry feed (21). Implementation of dry inoculation procedures for spices would also prevent release of water-soluble antimicrobials (43), which may artificially reduce microbial numbers in the absence of processing. In addition to the method of inoculation, the media used and the physiological state of the inoculant cells during inoculum preparation should also be considered.

Improved Salmonella survival under a variety of environmental conditions, including desiccation, starvation, and acidity, has been reported for cells grown on agar and cells within biofilms compared with planktonic cells (19, 20). Thermal destruction curves of agar-grown cells of Salmonella serotypes Tennessee and Oranienburg were more linear than those for planktonic cells cultured in liquid; however, overall thermal resistance in the test product was similar (23). Incorporation into biofilms increases the resistance of Salmonella to a variety of adverse conditions, including heat (2), presence of antimicrobials (9, 29), moderate acid conditions (45), and desiccation (1). Physiological state at the time of inoculation has been reported to influence the recovery of Salmonella Tennessee after desiccation and storage in dry milk powder (1).

The objective of this study was to compare the effects of inoculation preparation on the recoverability and stability of $S$. enterica serotypes on whole black peppercorns and cumin seeds during 28 days of dry storage $\left(a_{w}=0.3\right)$. Recoverability was compared for Salmonella inoculated using one dry inoculation method and three wet inoculation methods followed by drying: Salmonella cells grown in tryptic soy broth (TSB), cells grown on tryptic soy agar (TSA), or cells grown in TSB with whole spices for $24 \mathrm{~h}$, likely resulting in inclusion of the cells within native microbiota biofilms formed around the seeds.

\section{MATERIALS AND METHODS}

Bacterial strains and growth conditions. Three $S$. enterica serovars isolated from low- $\mathrm{a}_{\mathrm{w}}$ foods (Tennessee K4643 from ConAgra peanut butter in 2010, Ball ARL-SE-085 from black pepper in 2011, and Johannesburg aRL-SE-013 from dried ginger in 2010) were used to inoculate whole black peppercorns and whole cumin seeds. Cultures from stocks kept at $-80^{\circ} \mathrm{C}$ were streaked onto TSA (BD, Franklin Lakes, NJ) and incubated for $24 \mathrm{~h}$ at $37^{\circ} \mathrm{C}$ to obtain isolated colonies. An isolated colony was transferred to xylose lysine Tergitol agar (XLT4; BD) and incubated for $24 \mathrm{~h}$ at $37^{\circ} \mathrm{C}$. Single colonies from XLT4 were transferred to TSB (BD) and incubated with shaking (180 rpm) for $24 \mathrm{~h}$ at $37^{\circ} \mathrm{C}$. Cells were washed three times in $10 \mathrm{ml}$ of $0.1 \%$ (wt/vol) peptone (Sigma-Aldrich, St. Louis, MO) with $0.1 \%$ Tween 80 (Fisher Scientific, Kansas City, MO) (PT) to remove excess nutrients and spent media. Peppercorns were inoculated with pure cultures of Salmonella Tennessee, and cumin seeds were inoculated with a cocktail of all three Salmonella strains.

Spice varieties and sources. Whole peppercorns and whole cumin seeds were obtained from a major national spice processor.
No additional treatments were applied to remove background microbiota after receipt of spices and before inoculation.

Inoculation methods. The effects of inoculation method on survival of Salmonella during a 28-day storage period were compared for whole peppercorns and cumin seeds individually. Spices treated using each of the inoculation methods were destructively sampled at $1,7,14,21$, and 28 days postinoculation. For each inoculation method, enough inoculated spice was prepared to allow for enumeration of two 10-g subsamples at each time point. For spices inoculated with the wet methods, the inoculated spices were spread out in a single layer on sanitized aluminum trays ( 46 by $66 \mathrm{~cm}$ ) and dried for $24 \mathrm{~h}$ at room temperature $\left(23\right.$ to $25^{\circ} \mathrm{C}$ ) in a biological safety cabinet (final $\mathrm{a}_{\mathrm{w}}=0.3$ ). After drying, the spices were held in a desiccator (43 to $45 \%$ relative humidity) at room temperature $\left(23\right.$ to $\left.25^{\circ} \mathrm{C}\right)$ until sampling.

Wet inoculation with Salmonella cells grown in TSB. Planktonic (TSB-grown) cells were cultured as described above and applied directly to the peppercorn or cumin seed surfaces. Washed cells suspended in $20 \mathrm{ml}$ of sterile PT buffer were applied to $50 \mathrm{~g}$ of dry whole seeds in 27-oz (70-ml) Whirl-Pak bags (Nasco, Modesto, CA) and massaged by hand for 1 min to evenly coat the seeds. To prepare enough inoculated spices per experiment, two 50-g bags of each spice were prepared, and all spices were combined into one batch before enumeration. This part of the study was performed with two biological experimental replicates per spice.

Wet inoculation with Salmonella cells grown on TSB. Overnight cultures of Salmonella were plated onto TSA plates (150 by $15 \mathrm{~mm}$; BD) and incubated for $24 \mathrm{~h}$ at $37^{\circ} \mathrm{C}$ to cultivate a lawn of bacteria. Cells were scraped from the agar surface with a sterile cotton-tipped swab and suspended in $9 \mathrm{ml}$ of PT buffer. Scraped cells were washed twice in sterile PT buffer, resuspended in $20 \mathrm{ml}$ of PT buffer, and mixed by pipetting to break up cell clumps. The washed cell suspension $(20 \mathrm{ml})$ was applied to $50 \mathrm{~g}$ of dry whole seeds in 27-oz Whirl-Pak bags and massaged by hand for $1 \mathrm{~min}$ to evenly coat the seeds. To prepare enough inoculated spices per experiment, two 50-g bags of each spice were prepared, and all spices were combined into one batch before enumeration. This part of the study was performed with two biological experimental replicates per spice.

Biofilm inoculation (24-h incubation of Salmonella and seeds in TSB). This methodology was adapted from the method used by Aviles et al. (1) to form biofilms around silica beads but instead using whole seed spices. Salmonella cells were incubated in TSB $(1 \mathrm{~cm}$ depth) containing dry whole peppercorns $(62 \mathrm{~g})$ or cumin seeds $(25 \mathrm{~g})$ arranged in a single layer on the bottom of a 2-liter Erlenmeyer flask. The Salmonella-seed mixture was incubated statically for $24 \mathrm{~h}$ at $37^{\circ} \mathrm{C}$, the liquid medium was decanted, and the seeds were washed by vigorously swirling for $30 \mathrm{~s}$ in PT buffer to remove nonadherent cells and nutrients from the seed surface. To prepare enough inoculated spices for the complete study, two flasks were used for peppercorns and four flasks were used for cumin seeds, 50-g bags per spice were prepared, and all spices were combined into one batch before enumeration. This part of the study was performed with two biological experimental replicates per spice. Wet mode environmental scanning electron microscopy was used with inoculated and noninoculated peppercorns to visualize biofilms. Peppercorns were stained according to the ruthenium red method described by Priester et al. (32) and 
visualized at $68 \%$ humidity, 4 Torr pressure, $5^{\circ} \mathrm{C}$, and an accelerating voltage of $10 \mathrm{kV}$ in an FEI Quanta 600 FEG environmental scanning electron microscope at the Nanoscale Characterization and Fabrication Laboratory (Institute for Critical Technology and Applied Science, Virginia Tech).

Dry transfer inoculation. Inoculation of spice seeds with Salmonella via dry contact transfer from an inoculated silica sand carrier was adapted from the method of Blessington et al. (7). A concentrated inoculum (10 $\log \mathrm{CFU} / \mathrm{ml})$ was prepared as described for the TSA wet inoculation method, and $3 \mathrm{ml}$ of the resuspended inoculum was applied to dry silica sand (40 to 100 mesh; Acros Organics, Morris Plains, NJ) in 20-g batches to achieve an average inoculum of $7.8 \log \mathrm{CFU} / \mathrm{g}$ on the sand. The Salmonella inoculum was incorporated evenly into the sand by stirring and mashing with a sanitized mortar and pestle for $1 \mathrm{~min}$. Inoculated sand was dried in a biological safety cabinet for $48 \mathrm{~h}$ to an $\mathrm{a}_{\mathrm{w}}$ of 0.30 . After drying, all batches were combined and stored at $4{ }^{\circ} \mathrm{C}$ in a desiccator for up to 7 days until used. The average loss of Salmonella on sand after drying was $0.72 \pm 0.18 \log \mathrm{CFU} / \mathrm{g}$.

Dry transfer of Salmonella to the seeds was performed by combining $25 \mathrm{~g}$ of inoculated sand with $50 \mathrm{~g}$ of spices in a WhirlPak bag and mixing by hand for $1 \mathrm{~min}$. Contents of the bag were then transferred to a sanitized container ( 8 by 8 in. [20.3 by 20.3 $\mathrm{cm}]$ ), covered with aluminum foil, and shaken for $24 \mathrm{~h}$ on a horizontal rotating platform (Barnstead International, Dubuque, IA) to maximize surface contact between seed and sand. After $24 \mathrm{~h}$, the sand-seed mixture was transferred to a sanitized sieve (standard no. 7, 2.8-mm mesh size; Fisherbrand, Pittsburgh, PA) and shaken by hand in a horizontal circular motion for $30 \mathrm{~s}$ to separate the sand particulates. To prepare enough inoculated spices per experiment, two 50-g bags per spice and $25 \mathrm{~g}$ of inoculated sand were prepared, and all spices were combined into one batch before enumeration. This part of the study was performed with two biological experimental replicates per spice.

Microbiological detection. Total aerobic bacteria and Salmonella were enumerated according to the following method. Seed samples $(10 \mathrm{~g})$ were homogenized in $90 \mathrm{ml}$ of sterile PT buffer for $60 \mathrm{~s}$ in a sterile filtered bag with a lab blender (Interscience BagMixer, Guelph, Ontario, Canada). For biofilminoculated spices, PT with $0.2 \%$ cellulase (Sigma-Aldrich) was used. The homogenized liquid was vacuum filtered through no. 4 qualitative filter paper (Whatman, GE Healthcare, Pittsburgh, PA) to remove small seed particulates that were otherwise transferred by serial dilution. The filtered homogenate was serial diluted 1:10 in sterile PT buffer. From appropriate dilutions, $100 \mu \mathrm{l}$ was spread plated onto duplicate XLT4 and TSA plates and incubated for 18 to $24 \mathrm{~h}$ at $37^{\circ} \mathrm{C}$.

Water activity and measurement. The $a_{w}$ of whole peppercorns $(3 \mathrm{~g})$ and cumin seeds $(5 \mathrm{~g})$ was determined with an $\mathrm{a}_{\mathrm{w}}$ meter (4TE, AquaLab, Pullman, WA). Peppercorns and cumin seeds were determined to have an $\mathrm{a}_{\mathrm{w}}$ of approximately 0.3 and 0.4 , respectively, before inoculation. The $\mathrm{a}_{\mathrm{w}}$ of noninoculated seeds prepared using the methods described above but without Salmonella was measured periodically for $48 \mathrm{~h}$ to identify the length of drying time needed to return the product to its original $\mathrm{a}_{\mathrm{w}}$; $24 \mathrm{~h}$ was determined to be a sufficient period to return both noninoculated whole spice seed and dry carrier (sand) samples to $a_{w}$ values comparable to those of the original substrates. Inoculated spices and sand were stored in glass jar desiccators (39 to $45 \%$ relative humidity) after inoculation and drying to minimize fluctuations in $a_{w}$ due to changes in relative humidity during storage.

Statistical analysis. Bacterial counts were log transformed to approximate a normal distribution. Two biological replicates were performed for each inoculation, and duplicate replication was used for enumeration of survival. Statistical analyses were performed using JMP statistical software (version 10, SAS Institute, Cary, NC). The effect of the inoculation method during 28 days of spice storage was compared for each spice at each time point using a one-way analysis of variance to test for differences in the average $\log$ reduction of recovered CFU per gram on both peppercorns and cumin seeds. Differences were considered significant at $P<0.05$.

\section{RESULTS}

Total aerobic plate count. The mean total aerobic bacteria of noninoculated spices was 8.3 and $6.45 \log \mathrm{CFU} /$ $\mathrm{g}$ for whole peppercorns and cumin seeds, respectively, when plated on TSA. No colonies with characteristic black centers indicative of Salmonella appeared on XLT4 plates from noninoculated spices.

On inoculated peppercorns, declines in total aerobic bacteria were minimal during the 28 days, with less than $1.5 \mathrm{log}$ reductions for spices inoculated with most methods (Fig. 1A). The TSB-grown method was the exception, with $2.81 \pm 0.06 \log$ reductions on day 14 . On cumin seeds, the total aerobic bacteria on seeds inoculated by biofilms was significantly higher that that for the other methods at each time point (Fig. 2A). Overall, small reductions of less than $1.5 \log \mathrm{CFU} / \mathrm{g}$ were detected.

Comparison of Salmonella survival by inoculation method and time. Salmonella recovery after 28 days of dry storage was affected by method of inoculation (Figs. 1B and 2B). Differences in $\log$ reductions associated with each inoculation method were compared at each time point on both selective (XLT4) and nonselective (TSA) media. Statistical differences in overall log reductions of recoverable Salmonella for at least one method of inoculation were observed at each time point for both peppercorns and cumin seeds (Figs. 1B and 2B).

Recovery of Salmonella from peppercorns inoculated using the biofilm method had nearly zero net change $(-0.04$ $\pm 0.07 \log \mathrm{CFU} / \mathrm{g}$ ) on XLT4 after 28 days, but larger reductions were observed on day 28 for samples inoculated using the dry transfer and TSA-grown methods (Fig. 1B). No significant differences in recovery were found between seeds inoculated using the TSA-grown method $(-0.75 \pm$ $0.04 \log \mathrm{CFU} / \mathrm{g})$ and the dry transfer method $(-0.74 \pm$ $0.06 \log \mathrm{CFU} / \mathrm{g})$. The greatest reductions in Salmonella, on average $-3.56 \pm 0.20 \log \mathrm{CFU} / \mathrm{g}$, were obtained with the TSB-grown method; therefore, this method was omitted from inoculation testing of cumin seeds.

Similar trends in results from the inoculation methods were observed for Salmonella recovered during storage of inoculated cumin seeds. Salmonella inoculated onto cumin seeds within biofilms had the least change $(-0.28 \pm 0.12$ $\log \mathrm{CFU} / \mathrm{g}$ on XLT4) during the 28 days, with slight increases at 1,7 , and 21 days rather than reductions 
A

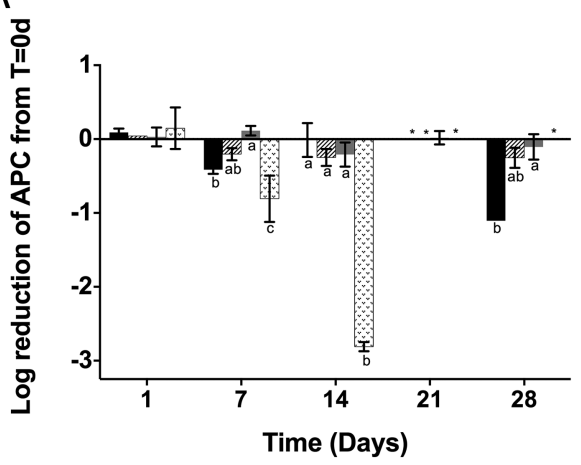

B

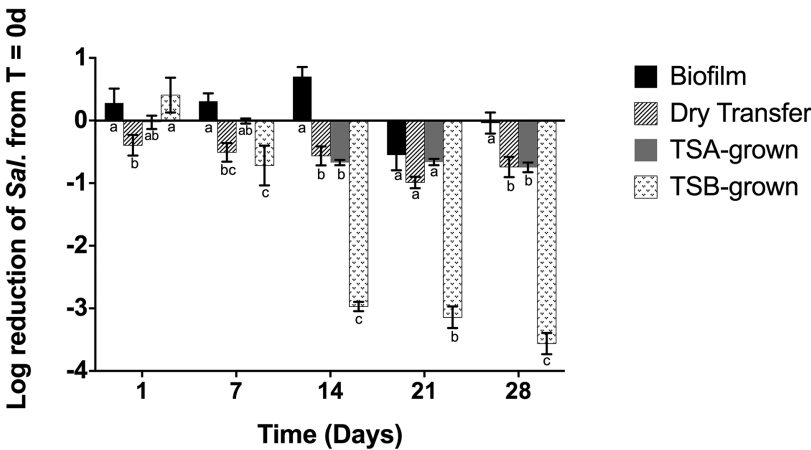

FIGURE 1. Comparisons of log reductions in CFU per gram of total aerobic bacteria (APC) and Salmonella recovered from peppercorn surfaces during 28 days of storage at $a_{w}=0.3$ after inoculation by various methods. Bars represent the average of two replicates; bars without with the same letter are significantly different. * Data not collected. (A) Total aerobic bacteria recovered from peppercorns on TSA. Data were not collected on days 21 and 28. Initial average inoculum per method after drying was $6.56 \mathrm{log}$ CFU/g for biofilm, $5.52 \mathrm{log}$ CFU/g for dry transfer, $7.56 \log C F U / g$ for TSA grown, and $8.15 \log C F U / g$ for TSB grown. (B) Salmonella recovered from peppercorns on XLT4. Initial average inoculum per method after drying was 5.19 log CFU/g for biofilm, $5.53 \log C F U / g$ for dry transfer, $6.79 \log C F U /$ $g$ for TSA grown, and $7.89 \log C F U / g$ for TSB grown.

(Fig. 2B). The greatest reductions of Salmonella were observed when cumin seeds were inoculated with the TSA-grown method, with overall reductions of $2.76 \pm 0.04$ $\log \mathrm{CFU} / \mathrm{g}$ on XLT4 at 28 days. Overall, these results indicated that the inoculation method affected the long-term recoverability of Salmonella from whole peppercorns and cumin seeds after drying compared with the initial recovery $24 \mathrm{~h}$ after inoculation.

\section{DISCUSSION}

Salmonella can survive in and has been implicated in illness associated with a variety of low- $\mathrm{a}_{\mathrm{w}}$ foods, including spices, after extended periods of dry storage (31). Dried milk powder, walnuts, and ground pepper can all support this pathogen for more than 30 days, and in some cases viability has been confirmed after 1 year of storage $(1,6$, 24). Survival of Salmonella in very low-moisture tahini $\left(a_{w}=0.17\right)$ was documented for up to 16 weeks (39). In the present study, Salmonella persisted in high numbers on the
A

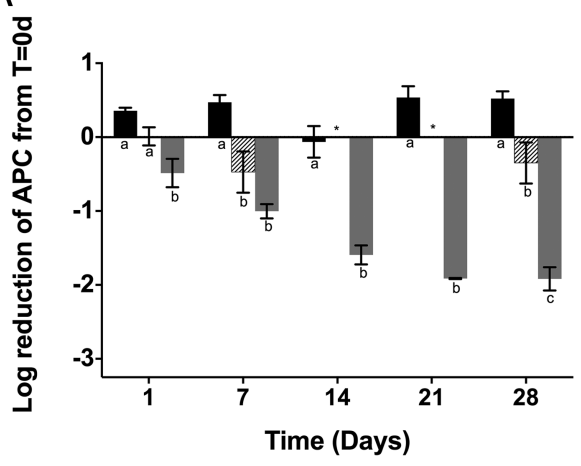

Biofilm Dry Transfer TSA-grown

B

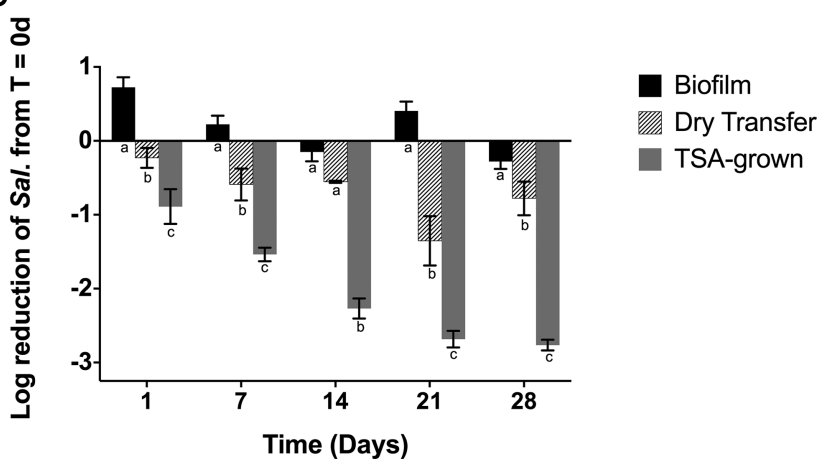

FIGURE 2. Comparisons of log reductions in CFU per gram of total aerobic bacteria (APC) and Salmonella recovered from cumin seed surfaces during 28 days of storage at $a_{w}=0.3$ after inoculation by various methods. Bars represent the average of two replicates; bars without with the same letter are significantly different. * Data not collected. (A) Total aerobic bacteria recovered from cumin seeds on TSA. Initial average inoculum per method after drying was $9.08 \mathrm{log} C F U / g$ for biofilm, $6.79 \mathrm{log}$ CFU/g for dry transfer, and $6.89 \log$ CFU/g for TSA grown. (B) Salmonella recovered from cumin seeds on XLT4. Initial average inoculum per method after drying was $8.46 \mathrm{log} C F U / g$ for biofilm, $6.47 \log$ CFU/g for dry transfer, and $6.55 \log$ CFU/g for TSA grown.

inoculated spices for the 28 days of storage at an $\mathrm{a}_{\mathrm{w}}$ of 0.3 . Log reductions in recoverable TSB-grown Salmonella Tennessee from whole peppercorns at 14 days $(-2.97 \pm$ $0.09 \log \mathrm{CFU} / \mathrm{g}$ ) were comparable to those previously reported for Salmonella Rubislaw $(-2.57 \log \mathrm{CFU} / \mathrm{g})$ in ground black pepper stored at $25^{\circ} \mathrm{C}$ and an $\mathrm{a}_{\mathrm{w}}$ of 0.66 for 15 days (33). Results were comparable only for the TSB-grown Salmonella inoculation method; much smaller log reductions of Salmonella Tennessee were noted for TSA-grown, biofilm, and dry transfer inoculation methods.

Inoculation method, among other factors such as growth phase, temperature, presence of glucose, trehalose, $\mathrm{NaCl}$, and speed of dehydration, has been reported to affect subsequent persistence of Salmonella under desiccation conditions (19). Increased desiccation tolerance of Salmonella grown on Luria-Bertani (LB) agar compared with planktonic cells has been reported on polystyrene plates stored at $4{ }^{\circ} \mathrm{C}$ and 40 to $45 \%$ relative humidity for more than 100 weeks (19). Agar-grown Salmonella survived dry storage better than did planktonic cells, with approximately 2-log higher levels of LB agar-grown cells recovered at 


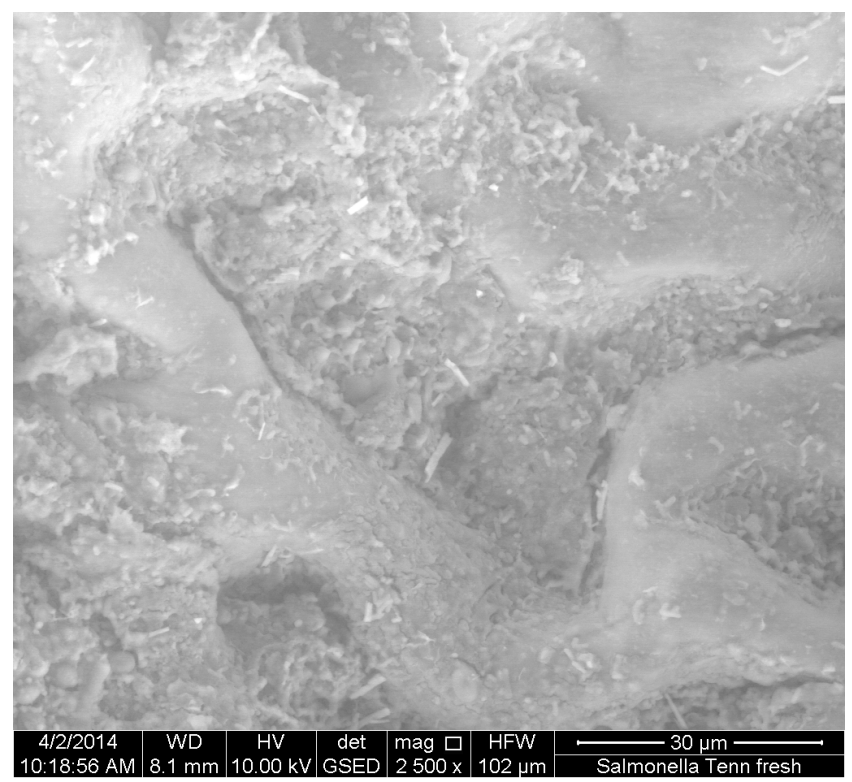

FIGURE 3. Environmental scanning electron microscopy image $(2,500 \times)$ of cells on peppercorn surface after biofilm inoculation method.

4 weeks, a period comparable to that of the present study (19). In the present study, the TSA-grown cells were quickly washed to remove residual nutrients. It is unknown whether the Salmonella cell physiology changed during these washing steps. However, there were differences in survival between TSA-grown and TSB-grown cells in the present study, with a $2.81-\log$ increase in recovery of TSA-grown cells compared with TSB-grown cells on peppercorns after 28 days. Because the main purpose of this study was to identify stable inoculation methods for spices for use in inactivation studies, we did not continue the evaluation of the TSB inoculation method for cumin seeds. In contrast to the small $\log$ reduction for TSA-grown cells on peppercorns, 2-log reductions were obtained for cumin seeds. This finding may reflect differences in spice properties, such as smaller surface area, different chemical composition, and smaller populations of native microbiota for cumin seeds compared with whole black peppercorns.

For each of the wet inoculation methods, the same medium rich in glucose was used for growth; however, some differences in physiological state may have been present. Other differences included the amount of liquid used for deposition of the inoculum. For the TSA and TSB methods, small volumes of liquid were applied across a larger volume of spice, likely resulting in only surface deposition of the Salmonella. In contrast, immersion of the spice within TSB for $24 \mathrm{~h}$ may have resulted in altered surface properties of the spice. It is not known whether Salmonella became internalized within the spice or whether nutrients other than those present in TSB were available. Keller et al. (24) found that a four-strain cocktail of S. enterica that included the same Salmonella Tennessee strain used here was able to grow when inoculated into ground pepper at an $\mathrm{a}_{\mathrm{w}}>0.97$ at $35^{\circ} \mathrm{C}$. In the present study, although some metabolism of the spice surface may have occurred, Salmonella probably was incorporated into or attached to the surface of a biofilm originating from the native microbiota of the spice during the $24 \mathrm{~h}$ of immersion in TSB. Environmental scanning microscopy of the wet peppercorns revealed small coccoid and rod-shaped cells $(\sim 7$ to $8 \mu \mathrm{m}$ ) encased within a mucoid layer (Fig. 3) after $24 \mathrm{~h}$ of immersion inoculation. The netlike structure was similar to that reported for other strains of Salmonella on inert surfaces, and the mucoid appearance of the spice was likely due to the production of exopolysaccharide and proteases by the bacterial biofilm community (46). Although it was not possible to visualize the location of the Salmonella cells in the biofilm, large populations of Salmonella were recovered from the spices even after vigorous washing to remove nonadherent cells. Some planktonic cells may have been present on the surface of the biofilm, which would be characteristic of typical biofilm dispersal; however, in previous studies the majority of biofilm cells were found encased within a matrix (47). One component of this matrix was cellulose, a critical component of Salmonella biofilms (38), whose presence was indicated based on the larger numbers of Salmonella cells recovered when the enzyme cellulase was added to the diluent buffer. The inclusion of cellulase may explain the small increases in Salmonella recovered from cumin seeds inoculated by $24-\mathrm{h}$ immersion method; cellulase would increase cell dissociation, resulting in more colonies. The native microbiota within the biofilm probably secrete other polysaccharides or proteins that can also encase the Salmonella cells and that addition of other enzymes could further enhance disassociation and enumeration. Alternatively, the inclusion of cellulase may aid in removal of Salmonella cells that may have been entrapped within the seed coat.

Although in the present study Salmonella was not definitely identified within the biofilm on these spices, previous research has indicated that encasement within biofilms increases bacterial resistance to various environmental and sanitation stresses, including organic acids (26, $45)$, desiccation $(16,44)$, and cleaning $(22)$. In the present study, no $\log$ reductions in Salmonella were detected after 28 days for either peppercorns and cumin seeds when the 24-h immersion inoculation method was used, further supporting the role of biofilms in resistance to desiccation. Desiccation tolerance in Salmonella has been highly associated with production of curli fimbriae, cellulose, and O-antigen (14-16, 44), which are also important components of Salmonella biofilms, promoting adherence to surfaces and to other bacteria $(44,47)$.

Salmonella cross-contamination in dry environments has been traced to transfer from contaminated equipment, dust in the air, and rodents $(3,12)$. The potential for dry transfer of Salmonella to low- $\mathrm{a}_{\mathrm{w}}$ foods supports the need for development of dry transfer inoculation procedures to mimic real-world contamination. Wet inoculation methods are particularly problematic for spices because introduction of liquid to the spice surface may allow growth of other native aerobic bacteria and fungi $(27,43)$, requiring lengthy drying of spices after harvest (36). The $\mathrm{a}_{\mathrm{w}}$ of dry products that have been previously introduced to water and then 
redried may not be the same as that of the original product (30). Moisture can also release antimicrobial compounds, which could interfere with the intended inoculation procedure (17).

Successful dry Salmonella inoculations include transfer from inoculated sand to walnuts and almonds and from inoculated chalk to pecans $(4,7)$. Transfer of Salmonella from silica sand resulted in 4.2 to $5.2 \mathrm{log} \mathrm{CFU} / \mathrm{g}$ on nut surfaces (7), which is comparable to the that obtained for dry transfer to peppercorns $(5.5 \pm 0.1 \log \mathrm{CFU} / \mathrm{g})$ but greater than that for cumin seeds $(6.5 \pm 0.06 \log \mathrm{CFU} / \mathrm{g})$. However, no further increase in transfer was achieved by altering the ratio of carrier to product and increasing contact time (results not shown). Log reductions in Salmonella Enteritidis after 30 days were approximately 0.5 to $1.5 \mathrm{log}$ $\mathrm{CFU} / \mathrm{g}$ on almonds and 0.6 to $1.25 \log \mathrm{CFU} / \mathrm{g}$ on walnuts (7). Comparable reductions in recovery of Salmonella Tennessee after 28 days were found in the present study for peppercorns and cumin seeds, suggesting that dry transfer of Salmonella from a sand carrier could be a useful inoculation method for whole spice applications where the carrier particles could be removed.

Prior exposure to low $\mathrm{a}_{\mathrm{w}}$, including desiccation, improves the survival of Salmonella when exposed to multiple stressors, such as those routinely experienced in food processing environments. Desiccated $S$. enterica serotypes Enteritidis, Hadar, Infantis, and Typhimurium exhibit enhanced tolerance to chemical disinfectants, dry heat, and UV irradiation (18). Tolerance of Salmonella Enteritidis to heat and hypochlorite stress has been reported as higher for cells grown at reduced $\mathrm{a}_{\mathrm{w}}$ (e.g., $\mathrm{a}_{\mathrm{w}}=0.94$ ) (25). Increased process times and/or elevated temperatures are necessary to kill Salmonella in a variety of low-a $\mathrm{a}_{\mathrm{w}}$ products, including almond kernels, rawhide, and alfalfa seeds $(5,8,42)$. Future studies should consider crossprotection, the physiological state of the pathogen cells, and inoculation methods when designing validation studies to assure inactivation of the most resistant Salmonella strains.

\section{ACKNOWLEDGMENTS}

Funding for this work was provided in part by a competitive grant from the International Life Science Institute of North America Subcommittee for Food Microbiology, by the Virginia Agricultural Experiment Station, and the Hatch Program of the National Institute of Food and Agriculture, U.S. Department of Agriculture. We would like to thank the U.S. Food and Drug Administration, Office of Regulatory Affairs, Arkansas Regional Lab for providing the spice-isolated strains. Special thanks go to Diana Woodrum for providing technical assistance and Stephen McCartney for performing the environmental scanning electron microscopy.

\section{REFERENCES}

1. Aviles, B., C. Klotz, J. Eifert, R. Williams, and M. Ponder. 2013. Biofilms promote survival and virulence of Salmonella enterica sv. Tennessee during prolonged dry storage and after passage through an in vitro digestion system. Int. J. Food Microbiol. 162:252-259.

2. Ban, G. H., S. H. Park, S. O. Kim, S. Ryu, and D. H. Kang. 2012. Synergistic effect of steam and lactic acid against Escherichia coli O157:H7, Salmonella Typhimurium, and Listeria monocytogenes biofilms on polyvinyl chloride and stainless steel. Int. J. Food Microbiol. 157:218-223.
3. Beuchat, L. R., E. Komitopoulou, H. Beckers, R. P. Betts, F. Bourdichon, S. Fanning, H. M. Joosten, and B. H. Ter Kuile. 2013. Low-water activity foods: increased concern as vehicles of foodborne pathogens. J. Food Prot. 76:150-172.

4. Beuchat, L. R., and D. A. Mann. 2011. Inactivation of Salmonella on pecan nutmeats by hot air treatment and oil roasting. J. Food Prot. 74: 1441-1450.

5. Beuchat, L. R., and A. J. Scouten. 2002. Combined effects of water activity, temperature and chemical treatments on the survival of Salmonella and Escherichia coli $\mathrm{O} 157: \mathrm{H7}$ on alfalfa seeds. J. Appl. Microbiol. 92:382-395.

6. Blessington, T., E. J. Mitcham, and L. J. Harris. 2012. Survival of Salmonella enterica, Escherichia coli $0157: \mathrm{H7}$, and Listeria monocytogenes on inoculated walnut kernels during storage. J. Food Prot. 75:245-254.

7. Blessington, T., C. G. Theofel, and L. J. Harris. 2013. A dryinoculation method for nut kernels. Food Microbiol. 33:292-297.

8. Chiewchan, N., W. Pakdee, and S. Devahastin. 2007. Effect of water activity on thermal resistance of Salmonella Krefeld in liquid medium and on rawhide surface. Int. J. Food Microbiol. 114:43-49.

9. Condell, O., C. Iversen, S. Cooney, K. A. Power, C. Walsh, C. Burgess, and S. Fanning. 2012. Efficacy of biocides used in the modern food industry to control Salmonella enterica, and links between biocide tolerance and resistance to clinically relevant antimicrobial compounds. Appl. Environ. Microbiol. 78:3087-3097.

10. D'Aoust, J. Y., J. Maurer, and J. S. Bailey. 2001. Salmonella, p. 141178. In M. P. Doyle, L. R. Beuchat, and T. J. Montville (ed.), Food microbiology: fundamentals and frontiers, 2nd ed. ASM Press, Washington, DC.

11. De Roin, M. A., S. C. Foong, P. M. Dixon, and J. S. Dickson. 2003. Survival and recovery of Listeria monocytogenes on ready-to-eat meats inoculated with a desiccated and nutritionally depleted dustlike vector. J. Food Prot. 66:962-969.

12. Du, W. X., M. D. Danyluk, and L. J. Harris. 2010. Efficacy of aqueous and alcohol-based quaternary ammonium sanitizers for reducing Salmonella in dusts generated in almond hulling and shelling facilities. J. Food Sci. 75:M7-M13.

13. Farkas, J. 2001. Physical methods of food preservation, p. 497-519. In M. P. Doyle, L. R. Beuchat, and T. J. Montville (ed.), Food microbiology: fundamentals and frontiers, 2nd ed. ASM Press, Washington, DC.

14. Finn, S., O. Condell, P. McClure, A. Amezquita, and S. Fanning. 2013. Mechanisms of survival, responses and sources of Salmonella in low-moisture environments. Front. Microbiol. 4:1-15.

15. Finn, S., J. C. Hinton, P. McClure, A. Amezquita, M. Martins, and S. Fanning. 2013. Phenotypic characterization of Salmonella isolated from food production environments associated with low-water activity foods. J. Food Prot. 76:1488-1499.

16. Gibson, D. L., A. P. White, S. D. Snyder, S. Martin, C. Heiss, P. Azadi, M. Surette, and W. W. Kay. 2006. Salmonella produces an $\mathrm{O}$-antigen capsule regulated by AgfD and important for environmental persistence. J. Bacteriol. 188:7722-7730.

17. Gray, R. J. H., and J. M. Pinkas. 2001. Gums and spices, p. 533-540. In F. P. Downes and K. Ito (ed.), Compendium of methods for the microbiological examination of foods. American Public Health Association, Washington, DC.

18. Gruzdev, N., R. Pinto, and S. Sela. 2011. Effect of desiccation on tolerance of Salmonella enterica to multiple stresses. Appl. Environ. Microbiol. 77:1667-1673.

19. Gruzdev, N., R. Pinto, and S. Sela (Saldinger). 2012. Persistence of Salmonella enterica during dehydration and subsequent cold storage. Food Microbiol. 32:415-422.

20. He, X., and J. Ahn. 2011. Differential gene expression in planktonic and biofilm cells of multiple antibiotic-resistant Salmonella Typhimurium and Staphylococcus aureus. FEMS Microbiol. Lett. 325: 180-188.

21. Hoffmans, C. M., and D. Y. C. Fung. 1993. Effective method for dry inoculation of bacterial cultures. J. Rapid Methods Autom. Microbiol. 1:287-294. 
22. Joseph, B., S. K. Otta, I. Karunasgar, and I. Karunasgar. 2001. Biofilm formation by Salmonella spp. on food contact surfaces and their sensitivity to sanitizers. Int. J. Food Microbiol. 64:367-372.

23. Keller, S. E., E. M. Grasso, L. A. Halik, G. J. Fleischman, S. J. Chirtel, and S. F. Grove. 2012. Effect of growth on the thermal resistance and survival of Salmonella Tennessee and Oranienburg in peanut butter, measured by a new thin-layer thermal death time device. J. Food Prot. 75:1125-1130.

24. Keller, S. E., J. M. VanDoren, E. M. Grasso, and L. A. Halik. 2013. Growth and survival of Salmonella in ground black pepper (Piper nigrum). Food Microbiol. 34:182-188.

25. Kieboom, J., H. D. Kusumaningrum, M. H. Tempelaars, W. C. Hazeleger, T. Abee, and R. R. Beumer. 2006. Survival, elongation, and elevated tolerance of Salmonella enterica serovar Enteritidis at reduced water activity. J. Food Prot. 69:2681-2686.

26. Kroupitski, Y., R. Pinto, M. T. Brandl, E. Belausov, and S. Sela. 2009. Interactions of Salmonella enterica with lettuce leaves. J. Appl. Microbiol. 106:1876-1885.

27. Mandeel, Q. A. 2005. Fungal contamination of some imported spices. Mycopathologia 159:291-298.

28. Nair, K. P. P. 2011. The agronomy and economy of black pepper (Piper nigrum L.) - the king of spices, chap. 1. In Agronomy and economy of black pepper and cardamom: the king and queen of spices. Elsevier, London.

29. O’Leary, D., E. M. Cabe, M. P. McCusker, M. Martins, S. Fanning, and G. Duffy. 2013. Microbiological study of biofilm formation in isolates of Salmonella enterica Typhimurium DT104 and DT104b cultured from the modern pork chain. Int. J. Food Microbiol. 161: 36-43.

30. Palipane, K. B., and R. H. Driscoll. 1993. Moisture sorption characteristics of in-shell macadamia nuts. J. Food Eng. 18:63-76.

31. Podolak, R., E. Enache, W. Stone, D. Black, and P. Elliot. 2010. Sources and risk factors for contamination, survival, persistance, and heat resistance of Salmonella in low-moisture foods. J. Food Prot. 73:1919-1936.

32. Priester, J., A. Horst, L. Van DeWerfhorst, J. Saleta, L. Mertes, and P. Holden. 2007. Enhanced visualization of microbial biofilms by staining and environmental scanning electron microscopy. $J$. Microbiol. Methods 68:577-587.

33. Ristori, C. A., M. A. D. Pereira, and D. S. Gelli. 2007. Behavior of Salmonella Rubislaw on ground black pepper (Piper nigrum L.). Food Control 18:268-272.

34. Roberts, T. A., J. L. Cordier, L. Gram, R. B. Tompkin, J. I. Pitt, L. G. M. Gorris, and K. M. J. Swanson. 2005. Spices, dry soups, and oriental flavorings, p. 360-391. In International Commission on Microbiological Specifications for Foods (ed.), Micro-organisms in foods 6: microbial ecology of food commodities, 2nd ed. Kluwer, New York.

35. Rushdy, A. A., J. M. Stuart, L. R. Ward, J. Bruce, E. J. Threlfall, P. Punia, and J. R. Bailey. 1998. National outbreak of Salmonella Senftenberg associated with infant food. Epidemiol. Infect. 120:125-128.

36. Schweiggert, U., R. Carle, and A. Schieber. 2007. Conventional and alternative processes for spice production-a review. Trends Food Sci. Technol. 18:260-268.

37. Sheth, A. N., M. Hoekstra, N. Patel, G. Ewald, C. Lord, C. Clarke, E. Villamil, K. Niksich, C. Bopp, T. A. Nguyen, D. Zink, and M. Lynch. 2011. A national outbreak of Salmonella serotype Tennessee infections from contaminated peanut butter: a new food vehicle for salmonellosis in the United States. Clin. Infect. Dis. 53:356-362.

38. Solano, C., B. García, J. Valle, C. Berasain, J.-M. Ghigo, C. Gamazo, and I. Lasa. 2002. Genetic analysis of Salmonella Enteritidis biofilm formation: critical role of cellulose. Mol. Microbiol. 43:793-808.

39. Torlak, E., D. Sert, and P. Serin. 2013. Fate of Salmonella during sesame seeds roasting and storage of tahini. Int. J. Food Microbiol. 163:214-217.

40. Van Doren, J. M., K. P. Neil, M. Parish, L. Gieraltowski, L. H. Gould, and K. L. Gombas. 2013. Foodborne illness outbreaks from microbial contaminants in spices, 1973-2010. Food Microbiol. 36: 456-464.

41. Vij, V., E. Ailes, C. Wolyniak, F. J. Angulo, and K. C. Klontz. 2006. Recalls of spices due to bacterial contamination monitored by the U.S. Food and Drug Administration: the predominance of salmonellae. J. Food Prot. 69:233-237.

42. Villa-Rojas, R., J. Tang, S. Wang, M. Gao, D. H. Kang, J. H. Mah, P. Gray, M. E. Sosa-Morales, and A. Lopez-Malo. 2013. Thermal inactivation of Salmonella Enteritidis PT 30 in almond kernels as influenced by water activity. J. Food Prot. 76:26-32.

43. Waje, C. K., H. K. Kim, K. S. Kim, S. Todoriki, and J. H. Kwon. 2008. Physicochemical and microbiological qualities of steamed and irradiated ground black pepper (Piper nigrum L.). J. Agric. Food Chem. 56:4592-4596.

44. White, A. P., D. L. Gibson, W. Kim, W. W. Kay, and M. G. Surette. 2006. Thin aggregative fimbriae and cellulose enhance long-term survival and persistence of Salmonella. J. Bacteriol. 188:3219-3227.

45. Xu, H., H. Y. Lee, and J. Ahn. 2010. Growth and virulence properties of biofilm-forming Salmonella enterica serovar Typhimurium under different acidic conditions. Appl. Environ. Microbiol. 76:7910-7917.

46. $\mathrm{Xu}, \mathrm{H} ., \mathrm{H}$. Y. Lee, and J. Ahn. 2010. Characteristics of biofilm formation by selected foodborne pathogens. J. Food Saf. 31:91-97.

47. Zogaj, X., M. Nimitz, M. Rohde, W. Bokranz, and U. Romling. 2001. The multicellular morphotypes of Salmonella Typhimurium and Escherichia coli produce cellulose as the second component of the extracellular matrix. Mol. Microbiol. 39:1452-1463. 